\title{
Effect of Governance Indicators on Under-Five Mortality in OECD Nations: Generalized Method of Moments
}

\author{
Sara Emamgholipour ${ }^{1}$, Zahra Asemane $^{2}$
}

${ }^{1}$ Ph.D. of Health Economics, Assistant Professor, Department of Management \& Health Economics, School of Public Health, Tehran University of Medical Sciences, Tehran, Iran

${ }^{2}$ M.Sc. of Health Economics, Department of Management \& Health Economics, School of Public Health, Tehran University of Medical Sciences, Tehran, Iran

\section{Type of article: Original}

\begin{abstract}
Introduction: Today, it is recognized that factors other than health services are involved in health improvement and decreased inequality so identifying them is the main concern of policy makers and health authorities. The aim of this study was to investigate the effect of governance indicators on health outcomes.

Methods: A panel data study was conducted to investigate the effect of governance indicators on child mortality rate in 27 OECD countries from 1996 to 2012 using the Generalized Method of Moments (GMM) model and EVIEWS.8 software.

Results: According to the results obtained, under-five mortality rate was significantly related to all of the research variables $(p<0.05)$. One percent increase in under-five mortality in the previous period resulted in a $0.83 \%$ increase in the mortality rate in the next period, and a $1 \%$ increase in total fertility rate, increased the under-five mortality rate by $0.09 \%$. In addition, a $1 \%$ increase in GDP per capita decreased the under-five mortality rate by $0.07 \%$, and a $1 \%$ improvement in control of corruption and rule of law indicators decreased child mortality rate by 0.05 and $0.08 \%$, respectively. Furthermore, $1 \%$ increase in public health expenditure per capita resulted in a $0.03 \%$ decrease in under-five mortality rate.

Conclusion: The results of the study suggest that considering control variables, including GDP per capita, public health expenditure per capita, total fertility rate, and improvement of governance indicators (control of corruption and rule of law) would decrease the child mortality rate.
\end{abstract}

Keywords: governance; child mortality rate; OECD; GMM

\section{Introduction}

According to programs of the World Health Organization (WHO), all nations around the world are committed to children's health in the form of "Health for All" by the year 2000, and half of the nations are obliged to decrease under-five mortality rate to two-thirds of the current rate by $2015(1,2)$. Considerations related to human development indicators, the objective expression of which could be observed in millennium development goals of the United Nations, have persuaded governments to supply a great part of expenditures related to these indicators. Another important reason of government's involvement in health expenditures is having better impact of the public sector relative to the private sector (3). In traditional economics texts, there are different views on the effect of different government expenditures on improvement of development indicators, and different results have been obtained in this regard. Some of these results suggest that government expenditures have no positive effect on related variables. Lack of effect or minimal effect of government expenditures on development indicators has two main justifications, i.e., 1) increasing government expenditures results in "crowding out" effect that leads to the replacement of public sector with private sector, which decreases the effect of increase in government expenditures

\section{Corresponding author:}

Assistant Professor Dr. Sara Emamgholipour, Department of Management \& Health Economics, School of Public Health, Tehran University of Medical Sciences, Tehran, Iran.

Tel: +98.2142933240, E-mail: s-emamgholipour@tums.ac.ir

Received: October 17, 2015, Accepted: December 10, 2015, Published: January 2016

iThenticate screening: December 10, 2015, English editing: January 03, 2016, Quality control: January 06, 2016

(C) 2015 The Authors. This is an open access article under the terms of the Creative Commons Attribution-NonCommercialNoDerivs License, which permits use and distribution in any medium, provided the original work is properly cited, the use is non-commercial and no modifications or adaptations are made. 
and 2) the lack of fruition of government expenditures because of bad governance that is the subject of the current study as well (4). Good governance is one of important and new issues in development literature that has been suggested since 1980 (5). According to the definition presented by the United Nations development program, good governance is management of public affairs based on the rule of law, efficient and fair judiciary system, and extensive participation of people in the process of governance. In other words, the more the rule of law is in effect, the more effective and fair the judiciary system becomes and the more people participate in the governance of the nation, resulting in better governance in that nation (6). The World Bank defines good governance based on six indicators, i.e., 1) voice and accountability, 2) political stability, 3) effectiveness and efficiency of government, 4) regulatory quality, 5) rule of law, and 6) control of corruption. Nations are scored between 2.5 and -2.5 or zero and 100 and higher score suggests better outcomes for that country (7-9). In nations with weak governance, public resources are wasted and are not converted into social investment; while these could result in favorable social outcomes, such as better education and health services for children (10). In addition, in various studies, it has been verified that there is a strong cause-and-effect relationship between good governance and better development outcomes, including higher per capita income, lower mortality, and longer life expectancy (9, 11-15).

\section{Material and Methods}

This was an analytical study and in the form of panel data model, i.e., a combination of time series and cross-section data that investigated the effect of governance indicators (control of corruption and rule of law) on under-five mortality rate in OECD member countries. The study samples were 27 members of OECD countries, i.e., Austria, Belgium, Canada, Denmark, France, Germany, Greece, Ireland, the Netherlands, Norway, Portugal, Spain, Sweden, Switzerland, England, the USA, Italy, Japan, New Zealand, Finland, Poland, Australia, Cyprus, the Czech Republic, Hungary, South Korea, and the Slovak Republic. Data related to governance indicators of nations, per capita income, under-five mortality rate, public health expenditure per capita, and fertility rate were extracted from the World Bank. Since the data were dynamic panel type, the Generalized Method of Moments (GMM) method and EVIEWS.8 software were used.

To estimate the model, first, an appropriate instrumental variable should be specified, and, in this case, the instrument was a lagged dependent variable. In this method, the reliability of the model was examined using the Sargan test. The null hypothesis of this test is based on the lack of correlation between error terms and instrumental variables. In addition, the reliability of the GMM estimation was related to lack of first and second order autocorrelation, where Arellano and Bond tests were conducted for first order autoregressive in the first differences. The null hypothesis was based on the lack of autocorrelation of differenced residuals. To use this method, the number of sections $(\mathrm{N})$ should be greater than the number of time periods $(\mathrm{T})(\mathrm{N}>\mathrm{T})$; in this study, the number of countries (27) was greater than the time periods (17). In this study, of six governance indicators, control of corruption and rule of law were selected to investigate their effects on outcomes of the health sector in the countries under study. The variables used were as follows:

- $\quad$ mru5: Under-five mortality rate that points to child mortality per 1,000 live births who die before reaching age five $(16,17)$

- $\quad$ pgdp: Per capita income (PPP\$)

- $\quad$ phce: Public health expenditure per capita

- cc: Control of corruption indicator

- $\quad$ rl: Rule of law indicator

- fer: Total fertility rate

Considering other studies conducted on factors that affect child mortality, some of the other factors were included in the model, i.e., improved water sources, female literacy rate, immunization rate, improved sanitation facilities, and physicians per capita. Finally, these variables were not statistically significant, and they were excluded from the model. One of the reasons the coefficients of the mentioned variables were not significant was that, in the countries we investigated, improved water sources, improved sanitation facilities, and immunization rate were constant over $98 \%$ within the study period. Finally, by transforming variables into logarithmic forms, the following model was estimated based on GMM:

$\log (\text { mru5 })_{\mathrm{i}, \mathrm{t}}=\alpha_{0} \log (\mathrm{mru} 5)_{\mathrm{i}, \mathrm{t}-1}+\alpha_{1} \log (\mathrm{pgdp})_{\mathrm{i}, \mathrm{t}}+\alpha_{2} \log (\text { phce })_{\mathrm{i}, \mathrm{t}}+\alpha_{3} \log (\mathrm{cc})_{\mathrm{i}, \mathrm{t}}+\alpha_{4} \log (\mathrm{rl})_{\mathrm{i}, \mathrm{t}}+\alpha_{5} \log (\text { fer })_{\mathrm{i}, \mathrm{t}}+\mathrm{u}_{\mathrm{i}, \mathrm{t}}$ $\mathrm{t}=1,2, \ldots ., \mathrm{T}$ and $\mathrm{i}=1,2, \ldots, \mathrm{N}$

where the $i$ and $t$ subscripts denote country and time, respectively. 


\section{Results}

According to the results of Table 1, in countries under study, under-five mortality rate in previous period and fertility rate have a significant positive effect $(p<0.05)$ on under-five mortality rate. While GDP per capita, public health expenditure per capita, and governance indicators, including control of corruption and rule of law, have a significant negative effect on under-five mortality rate $(p<0.05)$. One percent increase in both under-five mortality rate in the previous period and the fertility rate increases the under-five mortality rate in the current period by 0.83 and $0.09 \%$, respectively. In addition, a $1 \%$ increase in GDP per capita, a $1 \%$ improvement in the control of corruption indicator, a $1 \%$ improvement of rule of law indicator, and a $1 \%$ increase in public health expenditure per capita, all of which resulted in $0.07,0.05,0.08$, and $0.03 \%$ decreases in the under-five mortality rate, respectively. Based on the results of Table 1, in this model, Sargan test statistic was obtained as 0.21, which shows the lack of correlation. Based on the results of Sargan test, instrumental variables are verified to be suitable. In other words, there was no correlation between instruments and error terms. Based on the Arellano and Bond tests, error terms should have first-order serial correlation AR (1), not a second-order serial correlation. In this model, first order AR (1) and second order AR (2) residuals correlation test (Arellano and Bond test) confirmed the results of estimated model based on GMM in 5\% (Table 2).

Table 1. Estimation results of model

\begin{tabular}{|l|l|l|l|}
\hline Variables & Coefficient & t-statistic & Prob. \\
\hline Lmru5 (-1) & 0.835109 & 88.21291 & 0.0000 \\
\hline Lpgdp & -0.074742 & -6.989014 & 0.0000 \\
\hline Lphce & -0.033084 & -18.05275 & 0.0000 \\
\hline Lfer & 0.099957 & 3.885371 & 0.0001 \\
\hline Lcc & -0.059643 & -2.216710 & 0.0274 \\
\hline Lrl & -0.087052 & -4.652295 & 0.0000 \\
\hline Sargan test & $0.212470 ;(\mathrm{p}<0.05)$ \\
\hline
\end{tabular}

Table 2. Results of the Arellano and Bond test

\begin{tabular}{|l|l|l|l|}
\hline Test order & Z-Statistic & rho & Prob. \\
\hline AR (1) & -1.993304 & -1.993304 & 0.0462 \\
\hline AR (2) & 1.655139 & 0.004559 & 0.0979 \\
\hline
\end{tabular}

\section{Discussion}

According to the research results, increase in GDP per capita decreases child mortality rate. In most studies, it has been shown that income has a great impact on health status. It could affect health status considerably through improving water sources, food and health services (18-23). Other studies suggest that there is a negative relation between mortality rate and GDP in such a way that by having more expenditure on health services, more attention to mother's nutrition, pre-natal and post-partum care, and early life of infants would provide the result of lowering the child mortality rate $(1,12,18-25)$. In studies conducted by Baldacci, Murray, Filmer, Pritchett, Kim, and Gwatkin, per capita income was recognized as one of the indicators that affect the child mortality rate $(12,18-23,25)$. Also, based on the results of the current study, increase in per capita public health expenditure decreases child mortality rate. In other studies, the effect of public health expenditure on health sector outcomes has been low, because of the negative effect of increasing public health expenditure on development of private health sector $(18,25,26)$. For instance, Filmer and Pritchett showed that the effect of health expenditure on under-five mortality rate was minimal and non-significant, and they concluded that health expenditure did not play a significant role in decreasing child mortality rate (18). However, in general, many researchers have verified the effect of public health expenditure on health outcomes $(22,27-30)$. In addition, as expected, increase in fertility rate has a positive and significant effect on higher child mortality rate. Results of this study comply with the results of a study conducted by Baldacci (25). Based on the results obtained, improving the quality of governance indicators (control of corruption and rule of law) has a negative effect on child mortality rate. Therefore, the results of studies by Kaufmann, Virmani, Lewis, Farag, and Olafsdottir confirmed the effect of governance on increasing health expenditure efficiency (9, 12-15). Furthermore, in different studies, a strong cause-and-effect relationship between good governance and better development outcomes, including higher per capita income, lower mortality, and higher life expectancy, has been established $(9,11-15)$. Investigating the effect of governance variables on health status, Kaufmann et al. used variables such as transparency, responsiveness, liability of codifications, and rule of law. The results showed that improving these variables was negatively related to child mortality (7). Murray et al. concluded that health 
expenditure has a significant effect on decreasing under-five mortality rate. The effect size of health expenditure on selected health outcomes is related to governance of that country, and good governance increases the effectiveness of health expenditures (17). Rajkumar and Swaroop demonstrated that in countries with weak governance, public expenditure has a minimal effect on outcomes; while in countries with good governance, public health expenditures have a significant effect on education and child mortality rate (11). Sabagh Kermani and Basakha used corruption and bureaucracy quality indicators as variables showing governance status and demonstrated that increasing educational and health expenditure was not always effective; however, in countries with better governance status, increasing these expenditures has had a greater impact on health and education indicators. In other words, improving governance indicators has enhanced the performance of health and education expenditures (4).

\section{Conclusions}

The findings of this study showed that increase in GDP per capita, public health expenditure per capita, and improving governance indicators of government, namely control of corruption and rule of law, have a negative effect, while fertility rate has a positive effect on child mortality rate in the current period. In addition, the positive relationship between child mortality rate in the current period and the previous period demonstrates that the more a country attempts to improve health status and decrease child mortality rate (as an indicator of health status) in the current period, the less child mortality becomes in a later period because of improvement in health status. The practical importance of these findings lies in the fact that governance status of nations affects health outcomes beside socio-economic and health factors. It is suggested that researchers consider governance quality indicators along with socio-economic and health factors to investigate improvement of health indicators and welfare in less developed or developing countries. In addition, conducting complementary research to consider the effect of each one of governance indicators could be a suitable path for later studies.

\section{Acknowledgments:}

The authors appreciate the staff members of the Tehran University of Medical Sciences who provided access to the network and library.

\section{Conflict of Interest:}

There is no conflict of interest to be declared.

\section{Authors' contributions:}

Both authors contributed to this project and article equally. All authors read and approved the final manuscript.

\section{References}

1) Shahraki Vahed A, Mardani Hamule M, Arab M, Firuzkuhi Z. Infant Under 1-59 Month Mortality Causes in Zabol. Journal of Nursing Research, 2010; 5(17):8.

2) Safari H, Nooripour S, Emadi E, Shakeri R, Jandaghi J, Mirmohammadkhani M. Associated Factors of Mortality of Children Aged 1 to 59 Months in Rural Areas of Semnan: A Nested Case-Control Study Based on 10 Years of Surveillance Data. Koomesh, 2014;15(3):8.

3) Basakha m. The Effect of Government Spending on Health and Education Outcomes in Health and Education in Islamic Countries. Tehran: Tarbiat Modares University; 2009.

4) Sabagh-kermani m, Basakha $\mathrm{m}$. The Role of Good Governance in Improving the Functioning of Government Spending: a Case Study of Health and Education Sectors in Islamic Countries. Faslname tahghighate eghtesadi, 1387;86.

5) Sharif-zade f, Gholi-pour r. Good Governance and the Role of Government. Management culture 2003;4:16.

6) Meidari A. Changes in the Policies of the World Bank and the Emergence of the Idea of Good Governance. Useful Letter, 2004(42):26.

7) Kaufmann D, Kraay A, Mastruzzi M. Governance matters VI: aggregate and individual governance indicators. World bank policy research working paper, 2007;4280.

8) Kaufmann D, Kraay A, Mastruzzi M. The worldwide governance indicators: methodology and analytical issues. Hague Journal on the Rule of Law 2011;3(02):220-246. DOI: 10.1017/S1876404511200046

9) Kaufmann D, Kraay A, Mastruzzi M. Governance Matters VII: Aggregate and Individual Governance Indicators, 1996-2007: World Bank, World Bank Institute, Global Programs Division, and Development Research Group, Macroeconomics and Growth Team; 2007. 
10) Gupta S, Verhoeven M, Tiongson ER. The effectiveness of government spending on education and health care in developing and transition economies. European Journal of Political Economy, 2002;18(4):717-737. DOI: 10.1016/S0176-2680(02)00116-7.

11) Rajkumar AS, Swaroop V. Public spending and outcomes: Does governance matter? Journal of development economics 2008;86(1):96-111. DOI: 10.1016/j.jdeveco.2007.08.003

12) Farag M, Nandakumar A, Wallack S, Hodgkin D, Gaumer G, Erbil C. Health expenditures, health outcomes and the role of good governance. International journal of health care finance and economics 2013;13(1):33-52. DOI: 10.1007/s10754-012-9120-3, PMid: 23266896

13) Virmani A, Sahu S, Tanwar S. Governance in the provision of public goods in south Asia. 2006.

14) Lewis M. Governance and corruption in public health care systems. Center for Global Development working paper, 2006(78). DOI: 10.2139/ssrn.984046

15) Olafsdottir AE, Reidpath DD, Pokhrel S, Allotey P. Health systems performance in sub-Saharan Africa: governance, outcome and equity. BMC public health, 2011;11(1):237. doi:10.1186/1471-2458-11-237

16) World Development Indicators. 2013, Available from: http://www.worldbank.org

17) Murray CJ, Laakso T, Shibuya K, Hill K, Lopez AD. Can we achieve Millennium Development Goal 4 ? New analysis of country trends and forecasts of under-5 mortality to 2015. The Lancet, 2007; 370(9592):1040-54. DOI: 10.1016/S0140-6736(07)61478-0

18) Filmer D, Pritchett L. The impact of public spending on health: does money matter? Journal of Social science \& medicine 1999;49(10):1309-23. DOI: 10.1016/S0277-9536(99)00150-1

19) Pritchett L, Summers LH. Wealthier is healthier. Journal of Human resources, 1996:841-68. DOI: $10.2307 / 146149$

20) Filmer D, Hammer JS, Pritchett LH. Weak links in the chain II: a prescription for health policy in poor countries. The World Bank Research Observer, 2002;17(1):47-66. doi: 10.1093/wbro/17.1.47

21) Gwatkin DR, Rutstein S, Johnson K, Suliman E, Wagstaff A, Amouzou A. Socio-economic differences in health, nutrition, and population. Washington, DC: The World Bank 2007.

22) Kim TK, Lane SR. Government Health Expenditure and Public Health Outcomes: A Comparative Study among 17 Countries and Implications for US Health Care Reform. American International Journal of Contemporary Research, 2013;3(9):8-13.

23) Kim D, Saada A. The social determinants of infant mortality and birth outcomes in Western developed nations: a cross-country systematic review. International journal of environmental research and public health, 2013;10(6):2296-2335. doi:10.3390/ijerph10062296

24) Frank R, Finch BK. Los Anos de la Crisis: an examination of change in differential infant mortality risk within Mexico. Social science \& medicine, 2004;59(4):825-35. DOI: 10.1016/j.socscimed.2003.11.028

25) Baldacci E, Guin - Siu MT, Mello LD. More on the effectiveness of public spending on health care and education: a covariance structure model. Journal of International Development, 2003;15(6):709-25. DOI: $10.1002 /$ jid. 1025

26) Wagstaff A. Socioeconomic inequalities in child mortality: comparisons across nine developing countries. Bulletin of the World Health Organization, 2000;78(1):19-29. DOI: 10.1590/S0042-96862000000100003

27) Anand S, Ravallion M. Human development in poor countries: on the role of private incomes and public services. The Journal of Economic Perspectives, 1993:133-50. DOI: 10.1257/jep.7.1.133

28) Bokhari FA, Gai Y, Gottret P. Government health expenditures and health outcomes. Health Economics, 2007;16(3):257-273. DOI: 10.1002/hec.1157, PMid: 17001737

29) Bidani B, Ravallion M. Decomposing social indicators using distributional data. Journal of econometrics, 1997;77(1):125-39. DOI: 10.1016/S0304-4076(95)01809-3

30) Samadi A, Rad EH. Determinants of Healthcare Expenditure in Economic Cooperation Organization (ECO) Countries: Evidence from Panel Cointegration Tests. International journal of health policy and management 2013;1(1):63. DOI: 10.15171\%2Fijhpm.2013.10, PMid: 24596838 PMCid: PMC3937933 